\title{
Familias multiasistidas y profesionales "multiembrollados": dificultades y potencialidades de la intervención en la institución
}

\section{Nerea Villanueva}

Agintzari SCIS

nereavillanuevagonzalez@yahoo.es

\section{Marta Aja}

Agintzari SCIS

marta@evntf-santpau.com

Gizarte-zerbitzuetan arazo anitzeko familiekin egunero egindako lanean oinarritzen da artikulu hau. Erakundeak esku hartu behar duenean sorturiko erronketariko bat, izan ere, profesionalak familia hauekin lan egitean aurkitzen dituen gatazkei buruz hausnartzea da. Artikuluan, beraz, profesionalak topatu ahal dituen bost nahaste azaltzen dira, kasu praktikoen adibideak eta konponbideak ere ageri direlarik.

\section{GAKO-HITZAK:}

Familia-eskuartzea, premia konplexuak, dilema profesionalak, zerbitzu-koordinazioa, burokrazia.
Este artículo surge del trabajo en el día a día con las familias multiproblemáticas desde los servicios sociales. Cuando la intervención tiene lugar en la institución, uno de los retos es reflexionar sobre algunos embrollos que se encuentra el profesional en la intervención con estas familias. Se describen cinco embrollos en los que puede verse envuelto el profesional ejemplificados con casos prácticos así como la resolución de cada uno de ellos.

\section{Palabras Clave:}

Intervención con familias, necesidades complejas, dilemas profesionales, coordinación de servicios, burocracia. 


\section{Introducción}

A lo largo de este artículo se abordan las dificultades que se encuentra el profesional que trabaja con familias multiasistidas desde un contexto institucional. Aunque también son conocidas como familias "multiproblemáticas", "desorganizadas" (Minuchin, 1967), etc., hemos elegido el término "multiasistidas", acuñado por Odette Masson en 1980 (Wainstein et al.; 2017: 299) aludiendo a las especiales relaciones que se establecen entre estas familias y los servicios que las atienden. En esas "especiales relaciones" es donde muchas veces se dan los embrollos con los que se encuentra el profesional que cuenta con su saber, con su saber hacer y con su saber ser para salir de ellos. El "embrollo" fue descrito por la Escuela de Milán (Selvini et al., 1986) para hacer referencia al juego relacional familiar caracterizado por la desconfirmación en el que se ve atrapado el hijo, participante en una coalición con uno de sus progenitores que luego será negada. De igual manera, los profesionales en el trabajo con estas familias podemos ser partícipes de juegos relacionales en los que nos coaliamos con otros profesionales o con miembros de las familias que atendemos, para finalmente sentirnos desconfirmados al no ser capaces de lograr aquellos objetivos que nos habíamos propuesto.

\section{El primer embrollo trata sobre la afectación} emocional en la interacción con las familias y el manejo de esta en el proceso de intervención; el segundo aborda la condición de obligatoriedad de la intervención para familias y para profesionales; el tercero hace referencia a la relación con otros profesionales que también están interviniendo con estas familias y las dificultades que surgen de ella. En el cuarto embrollo se detalla la influencia que tiene la progresiva burocratización de la intervención y en el quinto se describe la importancia del manejo de los tiempos en el proceso de cambio, así como la cronicidad de situaciones a las que se enfrenta el profesional. Este artículo trata de poner el foco en claves y propuestas de abordaje y cuidado del profesional que trabaja con estas familias. Minuchin decía que "Si el terapeuta no puede asociarse a la familia y establecer un sistema terapéutico la reestructuración no puede producirse y todo intento de alcanzar los objetivos terapéuticos fracasará" (Minuchin; 1974: 183). De ahí la importancia de reflexionar sobre el papel del profesional y los embrollos en los que se puede ver envuelto en el trabajo con las familias multiasistidas.

\section{Primer embrollo: lidiar con las emociones que se activan en la interacción con las familias}

El primer embrollo con el que nos encontramos es que el profesional tiene que lidiar con las emociones que se activan en la interacción con las familias.
Los relatos sobre situaciones de violencia, o la descarga de rabia y enfado por parte de los miembros de la familia hacia el sistema profesional, elevan la ansiedad, generan situaciones de tensión y pueden bloquear 0 activar al profesional. En estas circunstancias se hace necesario el desarrollo de habilidades y de actitudes por parte del profesional que permitan que el encuentro profesional-familia genere contextos profesionales de cambio en lugar de bloqueos, impasse, mimetización con el sistema familiar, etc. En la intervención con familias multiasistidas, el profesional se enfrenta a situaciones que pueden paralizarle a nivel cognitivo, emocional y pragmático. Según Giovanazzi, "se suelen generar escenas dramáticas cargadas de alta emotividad que pueden ir acompañadas de violencia psicológica y/o física" (Giovanazzi, 2009: 169). Campanini añade que "tenemos que llevar adelante la entrevista, incluso con personas que pueden despertarnos sentimientos de rabia, de antipatía o que pueden causarnos dificultades" (Campanini, 2012: 1.176).

En una entrevista, un padre explica que su hijo adulto con un $65 \%$ de discapacidad consiguió la pensión correspondiente porque en la entrevista de valoración supo hacerse muy bien el tonto, negando la familia las dificultades del día a día y, por supuesto, la discapacidad. Los mitos que la familia construye para minimizar el sufrimiento de acontecimientos dolorosos o para intentar salvaguardar su imagen pueden generar también un fuerte impacto emocional en el profesional, ya que la cultura del profesional es puesta en cuestión. Posiblemente, familia y profesional van a tener diferentes visiones del mundo y darán significados diferentes a lo que ocurre alrededor. Si la familia se desvía mucho de las creencias del profesional y este no es consciente de ello, puede plantear intervenciones erróneas o tomar decisiones equivocadas que perjudiquen a la familia que ha acudido a pedir ayuda.

El manejo del impacto emocional en la interacción con estas familias va a requerir por parte del profesional no solo de un buen nivel de conocimientos y técnicas, sino también, como señala Coletti (Coletti, 1997), de conciencia con respecto a las dificultades que pueden surgir frente a situaciones que despiertan ansiedades. Además de conocimientos, técnicas y registros es importante reconocer las emociones que suscita el trabajo con estas familias, y considerarlas según Virginia Satir como un termómetro de nuestro estado interno: "Al reconocer las emociones, nos encontramos en condiciones de manejarlas y estaremos mejor capacitadas para ver, escuchar y tomar decisiones sin el estorbo de un dialogo interior" (Satir, 1983: 223224). Las emociones activarán en el profesional unos conocimientos u otros, mediatizarán las técnicas a utilizar y, por supuesto, lo que va a registrar. La capacidad del profesional para gestionar las emociones durante la entrevista le puede ayudar a discriminar que la respuesta que da a la familia no tiene que ver con algo que ha sucedido en su vida 
personal y le facilitará tener alternativas de actuación en cualquier situación en la que se sienta atrapado (Satir, 1983).

Sin embargo, las familias multiasistidas no solo pueden paralizar al profesional, sino que en ocasiones le mueven a la acción. Para Ricardo Ramos las conversaciones que se dan en las entrevistas entre el profesional y la familia multiproblemática "generan un fuerte impacto emocional, impresionan y mueven a la acción" (Ramos, 2015: 41). Estos discursos que mueven a la acción pueden ser un discurso para una acción transformativa o puede ser un discurso para una acción reflexiva. En "el discurso para la acción transformativa, la conversación finaliza con una acción imperativa” (Ramos, 2015: 42); por ejemplo, una profesional recibe una llamada telefónica de una colega que ha acudido a realizar una valoración de dependencia de una señora de ochenta años que vive con su hija de cincuenta y dos. En la conversación, le informa de que la vivienda se encuentra en malas condiciones de higiene, hay plaga de insectos, mal olor y suciedad. La profesional queda en intervenir con la situación, realiza una visita a domicilio y busca un recurso que se encargue de la desinfección, la limpieza de la vivienda y, mientras se realiza, del alojamiento de la familia. En esta situación la familia activa al profesional. En el discurso para una acción reflexiva, la entrevista finaliza con una acción en diferido, es decir, el profesional propone una acción y pide una nueva entrevista para seguir conversando sobre el tema porque no está claro ni cerrado (Ramos, 2015: 43-44). La diferencia con la anterior es que la profesional actúa en interacción con el otro, comprende la situación y busca con el otro cuál es la mejor acción.

Siguiendo con el ejemplo, la profesional en la visita a domicilio comprueba la falta de higiene, establece relación con la hija e intenta conocer la situación de la familia; conecta con su situación de desbordamiento de cuidadora única y finaliza la visita quedando en seguir en contacto. En la siguiente visita, al día siguiente, habla con la hija sobre las condiciones de higiene de la vivienda y le facilita teléfonos de empresas para la limpieza. Con esta acción en diferido se introduce una temporalidad que facilita la narrativización y además es el cauce para comprender la complejidad de la situación (Ramos, 2015: 43-44). Tres días después la profesional acude al domicilio y se encuentra la casa limpia; la hija había contratado la limpieza y durante esta se habían alojado dos días en un hotel. Con esta intervención la familia ha podido activar sus propias capacidades y recursos acompañada de la profesional, que se ha dado un tiempo prudencial que le ha permitido vincularse con la familia, comprender la situación y activarla en la búsqueda de la solución.

¿Y qué nos lleva a sustituir a la familia en lugar de activarla? Según Coletti (1997) la angustia y la irritación que provoca la pasividad por parte de la familia ante el problema, o el hecho de que no tomen decisiones para salir de la situación. Esta angustia puede llevar al profesional a tomar decisiones desde la urgencia que generalmente tienden más a sustituir y reparar que a movilizar a la familia. Cuando se actúa desde la urgencia se pierde la posibilidad de evaluar y comprender la situación y el recurso o la intervención propuesta suelen fracasar, a la vez que la familia recibe un mensaje de desconfianza en sus propios recursos y capacidades, que las tiene, por débiles que sean. En circunstancias normales al profesional no se le ocurriría mover un buey, pero a veces puede ponerse a movilizar a la familia cuando no hay motivación para el cambio. Además, si la familia no se mueve, por lo general se tiende a pensar que sus integrantes son muy disfuncionales y se suele hacer una atribución externa en términos de causa efecto: "Si les propongo esta solución/ recurso/intervención y ellos no la aceptan es que no tienen interés, no se preocupan, no tienen conciencia...”, etc.

Otras veces nos encontramos con un exceso de motivación profesional que según Coletti (1997) se trata de un delirio de omnipotencia que lleva a que el profesional se sobreimplique en la intervención. En estas ocasiones será importante reflexionar sobre los motivos que le han llevado a elegir esta profesión. En el libro La vida personal del terapeuta, Guy señala que a veces "elegimos la profesión, entre otras razones, para lograr sanar alguna herida personal y, aun siendo así, se puede llegar a ser un profesional eficaz siempre y cuando la propia perturbación no sea tan significativa como para impedirnos atender las perturbaciones ajenas" (Guy, 1987: 42).

A continuación presentamos a la familia de Ángela, un caso en el que el servicio recibe la llamada telefónica de una trabajadora social que pregunta si podríamos atender a una familia en la que el padre ha intentado ahorcar a la hija mayor tras un episodio de coma etílico. Se trata de una familia a la que el hospital informa que la hija de catorce años está en urgencias. Los padres acuden al hospital y allí se enteran de que la niña ha estado "tirada" en un banco hasta que alguien llamó al 112. El padre pide que se haga un examen para ver si la hija ha sido violada. En el hospital, ante la falta de indicios, no realizan la exploración, por lo que el padre la lleva a otro hospital, donde también se niegan a explorar a la menor. Regresan a casa y el padre intenta ahorcarla. Un familiar que se encontraba en ese momento en la casa consigue ayudar a la hija a liberarse del padre y la menor escapa corriendo de la casa. La madre sale tras ella, llama a la policía e interpone denuncia contra el padre. Los padres de Ángela, Antonio y Merche tienen tres hijos: Ángela, de 14 años de edad; Antonio, de 11; y Carlos, de 6. La familia procede de Colombia, emigraron hace seis años tras perder todo su dinero. En Colombia, Antonio trabajaba de notario y Merche de secretaria. Actualmente, Antonio se ocupa de las tareas domésticas y de gestionar el día a día de la familia: crianza de los hijos, trámites administrativos, colegios, etc., mientras Merche trabaja como empleada doméstica. No se les conocen amistades 
salvo la relación que mantienen con un familiar de Merche que vive en el mismo pueblo.

En cuanto a las familias de origen, Antonio es el hijo pequeño de cinco hermanos. Sus progenitores se divorcian cuando él tiene 18 años. A los ocho años le enviaron a una escuela militar a otro país para estudiar hasta que ingresó en la universidad. Merche es la mayor de seis hermanas y un hermano. Describe a su familia como unida, de mujeres que cuidan todas unas de otras, con valores y respetuosos con las normas. La pareja se conoce a los dieciocho años y tras dos años de noviazgo él le propone matrimonio a la vez que le cuenta que también tiene relaciones con otras mujeres. Merche decide romper la relación, pero un año después contraen matrimonio.

A continuación se describen algunos fragmentos de las primeras entrevistas con esta familia. Como el padre no vive en la casa, por la orden de alejamiento hacia la hija, se realizan entrevistas con la madre y los hijos y sesiones con el padre. En las entrevistas, la madre se muestra ambivalente ante los hechos sucedidos: a veces piensa que la vida de la hija corrió serio peligro y otras duda de si fue para tanto. Considera que los niños no se enteraron de casi nada porque estaban dormidos en su habitación y que es mejor que no se hable del tema. Se muestra quejosa porque desde el "lío", como ella llama a lo que sucedió, tiene que encargarse de todo. El hijo mediano cree que la madre no es capaz de encargarse de la familia y que es necesario que su padre vuelva a casa porque es el que sabe hacer las cosas; opina que la responsable de la situación de la familia es su hermana, ya que si no hubiese tomado alcohol no habría pasado nada de esto. El hijo pequeño no deja que se hable del "lío"; cuando sale el tema interrumpe e intenta desviar la conversación a otros temas.

La hija está planteándose regresar al país de origen con una tía materna; refiere que si ella es el problema "prefiere no estar aquí y no volver a ver al padre". La madre cree que esta decisión es responsabilidad de la hija, lo que ella decida estará bien y ella está a la espera de la resolución judicial para tomar la decisión de separarse o no: si el padre es declarado culpable se divorcia, si es inocente, todo volvería a ser igual. En la entrevista con el padre, cuando se explora el intento de homicidio, refiere: "No recuerdo muchas cosas, solo recuerdo que un primo estaba en mi casa. Se me borra la memoria cuando salimos del hospital a las cuatro de la mañana. Espero que mi hija esté bien, espero que todo esto no la llene de rabia, que no le afecte". En la entrevista se observa que su interés es que los culpables cumplan su castigo por haber cometido un delito (hay que recordar que él estaba convencido de que su hija había sido violada). Explica que su situación es extraña porque sigue siendo "socio del club" (en referencia a la familia) pero es "como si le hubiesen retirado el carnet".

En otro caso, el juez solicita a los servicios sociales una valoración sobre la situación familiar de
Mikel, de doce años de edad, debido a que tras una discusión entre sus progenitores el padre ha prendido fuego al domicilio familiar. Mikel es hijo de José, de 47 años, y María, de 46. Tienen otro hijo en común de 22 años de edad. María tuvo otra hija fruto de una relación extramatrimonial, que finalmente fue dada en adopción a los tres años. La madre informa de que durante este embarazo su marido la acompañó, estuvo consumiendo drogas y cuando dio a luz en el hospital, ante el rechazo explícito hacia la niña, le ofrecieron la posibilidad de ceder la guarda y ella no quiso. Después del nacimiento, decidió que el padre biológico se encargase de la niña, ya que no podía llevarla a casa porque al ser negra todo el mundo sabría que su marido era un "cornudo" y no podía hacerle eso. Además, este no la admitía en casa. La niña estuvo un tiempo con el padre biológico, que en poco tiempo cedió la tutela al servicio de protección de menores. Durante doce años la familia convive con la familia de origen de María hasta que se trasladan a su propio domicilio, momento en el que ella sitúa el origen de los conflictos conyugales.

En este caso, tras un forcejeo que mantiene la pareja, al intentar él quitarle el móvil a ella para evitar que consiga droga, María denuncia a José por violencia de género. Ambos reconocen en el juzgado que han consumido alcohol y drogas, consumo que según ellos motiva las diferentes disputas familiares que mantienen con frecuencia. El hijo mayor relata al juez que es su padre quien sigue un tratamiento más continuado y no así su madre; no cree que su madre este capacitada para cuidar de su hermano menor. Ambas partes reconocen al juez la necesidad de ponerse en tratamiento, o de continuarlo en el caso del padre, y que la violencia se debe principalmente al consumo de alcohol y drogas. Al día siguiente José denuncia a María por maltrato psicológico. Argumenta que es menospreciado y menoscabado en su integridad moral con frases de carácter despectivo y humillante: "Si te vas a suicidar hazlo en tu trabajo, para que así cobre más, eres un inútil...". El juez establece como medida cautelar que María no puede acercarse a José a una distancia inferior a 500 metros y está obligada a abandonar el domicilio familiar; tampoco puede comunicarse con él durante la tramitación del procedimiento y se atribuye al padre la guarda y custodia del hijo menor; así como el disfrute de la vivienda. Se establece un régimen de visitas y comunicación materno-filial. El hijo mayor y la abuela materna son designadas para recoger y entregar al menor a la madre en un punto de encuentro familiar.

Diecinueve días después, José solicita al juez que se deje sin efecto la orden de protección dictada en su favor contra su esposa, argumentando que el hijo mayor le ha comunicado que la madre se ha puesto en tratamiento psiquiátrico de inmediato tras ocurrir los hechos y que está acudiendo a todas las citas (como era el consumo de drogas el que generaba violencia, ahora que están en tratamiento entienden que ya no tiene sentido la orden de protección). 
Anticipa al juzgado que no tienen intención de separarse y desean reanudar cuanto antes su vida en común por el bien de la familia. Mikel no comprende por qué sus padres no pueden vivir juntos cuando eso es precisamente lo que todos desean, teniendo que ver a su madre solo un día a la semana. Un mes después de que José solicite que se deje sin efecto la orden de protección, incendia la vivienda. Se decreta prisión provisional para él.

Mikel está en tratamiento psicológico en el centro de salud mental desde hace año y medio, después de haberse encontrado al padre tras un intento autolítico en el domicilio. Académicamente está obteniendo buenos resultados y el centro escolar no refiere problemas. Duerme con la madre y ha llegado a manifestarle que "ahora que no está el padre, en casa manda él". Manifiesta que sus padres se pegan uno a otro pero cree que la madre es más víctima de los insultos del padre que al revés. Cuenta que la madre le pide que llame al padre, que le visite, etc., con el fin de ayudarle, ya que el padre es percibido por la familia como el más perjudicado por la situación actual. Cuando Mikel visita al padre en la cárcel, este le pide que cuide de la madre y de la familia. Cree que la violencia es consecuencia del consumo de drogas de sus padres y explica que su padre incendió la casa porque el médico no le derivó a una comunidad terapéutica. No quiere pensar en el hecho de haber sido el único miembro de la familia que ha perdido la mayor parte de sus pertenencias en el incendio, para evitar enfadarse. El hermano mayor trabaja en una empresa, tiene novia y está pensando en independizarse. Aporta el sueldo a la economía familiar. La madre explica que el incendio se produjo porque el médico no había derivado a su marido a una comunidad terapéutica y que ella consumía porque la oficina de empleo no le daba un trabajo. Cuenta que en los últimos seis años su marido ha hecho seis intentos autolíticos, según ella, cuando él cree que ella le va a dejar y está con él porque no quiere que el padre de sus hijos se quite la vida por ella, dice "icómo justificar esto a mis hijos!”.

Actualmente, ambos progenitores se plantean propósitos de cambio: están siguiendo tratamiento, el padre intenta salir así de la cárcel, la madre en tratamiento ambulatorio. Todos los miembros de la familia desean la inmediata reunificación familiar y creen que la causa de los problemas de la familia es la droga y la falta de recursos asistenciales para su tratamiento. Si nos paramos a escuchar qué es lo que provoca a nivel emocional el relato de estos dos casos, es posible que surjan sentimientos de miedo por tener que afrontar una entrevista con personas que ejercen violencia; impotencia ante el encargo del juez o del derivante; estupefacción y asombro ante la posibilidad de que un padre acabe con la vida de una hija o que prenda fuego al domicilio familiar, y que una madre rechace a una hija por la raza o que perciba como víctima al padre que intenta matar a una hija; confusión ante la maraña de informaciones de órdenes de protección y solicitudes de retirada de estas; preocupación por si pasa algo más grave mientras se está interviniendo; rabia y tristeza porque sucedan este tipo de hechos, etc.

\section{El manejo las emociones del terapeuta, un factor clave para el cambio}

Una vez que conocemos que el contacto con estas familias genera impacto a nivel emocional, hemos de tener en cuenta cómo se puede manejar para evitar ser atrapado por el "cerco de goma" de la familia (Wynne et al., 1958; Singer, Wynne y Toohey, citados en Sluzki, 2007) y poner la distancia emocional adecuada que permita potenciar el cambio del sistema familiar. Estas emociones que surgen en el primer contacto con el caso, incluso antes de estar con la familia, ya sea a través de informes, reuniones, etc., van a seguir interaccionando durante el proceso de intervención, por lo que será necesario tenerlas en cuenta para manejarlas y que no interfieran como factor homeostático.

La emoción tiene que ser la alarma, la campanilla que avise al profesional de la posible dificultad que va a encontrar en la sesión y así pueda diseñar la estrategia para poder manejarla. En general, suele ayudar tratar de comprender lo que a priori genera tal impacto emocional en el profesional que le resulte incomprensible. En definitiva, se trata de buscar un significado a lo que pasó. El profesional tiene que tratar de comprender, que no justificar, y para ello las emociones que suscitan los casos pueden ayudar. Así:

- si genera pena uno de los miembros de la familia habrá que tener especial cuidado en no coaliarse o sobreimplicarse con ese miembro;

- si suscita pereza atender el caso, legitimar esa pereza por todo lo que implica a nivel emocional para el terapeuta un caso así, apoyarse en el equipo y a ser posible trabajar con estas familias en coterapia;

- si hay algún miembro con el que resulta más difícil interactuar, una de las máximas en estas situaciones es mantener una actitud de curiosidad por conocer y comprender; en caso de no poder con la situación, lo más legítimo es expresar que no se puede ayudar y derivar el caso o pasarlo a otro compañero/a si se pudiera, de ahí la importancia de contar con un equipo bien avenido para trabajar con estas familias;

- si genera estupefacción el hecho de que la familia niegue o minimice el problema de violencia grave o las consecuencias de los hechos, habrá que preparar estrategias para que en la sesión se maneje esa minimización del problema; el profesional tendrá que estar preparado para que la estupefacción no le impida construir un espacio donde se explicite la existencia de la violencia, cómo afecta a nivel emocional a cada uno de los miembros de la familia, cómo se protegen del sufrimiento, etc. 
Por ejemplo, en el caso de Ángela, una de las primeras reacciones fue: "¡Cómo un padre puede intentar matar a su hija!”. Esa estupefacción tiene que llevar a adoptar una postura de curiosidad respetuosa para entender desde dónde se produce, darle un significado a los hechos y así se pudo mostrar interés por la infancia y la historia de este padre y descubrir que emocionalmente estaba muy roto. Estuvo en una escuela militar desde los ocho años y por su relato se sospecha que fue agredido sexualmente. La posibilidad de una agresión sexual hacia la hija le conecta con su sufrimiento sin elaborar y le lleva al acting out. En el caso de Mikel, la preocupación que surge ante el relato que hace la familia de episodios de violencia grave que se dan con frecuencia, a la vez que insisten en que el deseo de todos es volver a estar juntos, lleva a intentar comprender qué función tenía la violencia y así hipotetizamos que la violencia formaba parte de la relación de la pareja. Los intentos autolíticos en el padre, las denuncias por violencia de género, etc., ponen a prueba el sistema conyugal llevando la violencia al límite como forma de poner a prueba al otro, "a ver si aun así vas a estar conmigo". Les da identidad, si no hay violencia al límite no hay garantía de que la pareja vaya a subsistir. La relación de pareja podría seguir la siguiente pauta: yo me siento reconocida/o por el otro en la medida en que las provocaciones le generan una reacción de atención a mi persona. Del relato de la familia se infiere que ambos pertenecen a familias en las que no han sido aceptados incondicionalmente ni reconocidos como sujetos dignos de ser queridos por sí mismos; la provocación del otro y su reacción extrema tiene la función de hacerles sentir importantes, reconocidos/as por el otro/a.

El momento en que se encuentra el profesional cuando recibe el caso también es una de las variables que ayudan a conectar con las emociones que provoca. Así, si se acaba de regresar de vacaciones al recibir a una de las familias presentadas, si su funcionamiento familiar genera mucha disonancia con la visión del mundo del profesional, o suscita pereza atenderlo, será necesario legitimar estas emociones por todo lo que implica a nivel emocional para el terapeuta un caso así y buscar apoyo y contraste, ya que abordar este tipo de problemáticas exige un trabajo en coterapia y contar con un equipo. También se pueden dar situaciones en las que las propias circunstancias de la vida del profesional legitimen que el profesional no se haga cargo de la familia y esta sea atendida por otro profesional.

Sin embargo, a los profesionales nos cuesta tomar conciencia de cómo las emociones que nos suscitan las familias que atendemos afectan a cómo nos relacionamos con ellas y a la intervención. Algunos de los motivos que pueden estar relacionados con esta dificultad tienen que ver con las características de los problemas que presentan estas familias (piénsese en los casos de maltrato, de separación, de violencia, marginalidad, de enfermedades terminales, etc.) que generan emociones como las descritas anteriormente. Así y todo, el profesional tiene que llevar adelante la entrevista, interaccionar con la familia y cumplir con la tarea, por lo que es posible que se obvien esas emociones que "incomodan" en pro de la tarea.

A veces pensamos que reconocer que la familia impacta emocionalmente en el profesional es signo de incompetencia profesional. Pareciera que da mejor imagen hablar del diagnóstico, del protocolo, del procedimiento... esto inviste de cierta profesionalidad. No se trata de negar el impacto emocional que provoca el relato de la familia, sino que lo importante será tomar conciencia de la emoción que sentimos para poder manejarla y evitar que la relación que establecemos con la familia se defina en función de la emoción suscitada. No está mal sentir o reconocer, por ejemplo, que una madre o un padre no caen bien, lo importante es qué respuesta se da a la emoción qué sentimos, qué hacemos con ella, cómo la gestionamos, es decir, qué y cómo vamos a hacer para evitar que la emoción de antipatía que nos genera esa persona nos impida aliarnos con ella. ¿Vamos a intentar conocerla a ver si empatizamos con lo que expresa? ¿Vamos a derivar el caso a una colega? ¿Se encargará de ella más la coterapeuta?

Otro aspecto importante que ayuda en el manejo de las emociones que suscita el trabajo con estas familias es tener en cuenta cómo se presenta la demanda. Según Juan A. Abeijón (1987) se ha descrito en ocasiones como un juego interrelacional a base de trampas a sortear en la relación, como pruebas que el demandante propone a su interlocutor. Un ejercicio interesante que ayuda a manejar estas "trampas" consiste en reflexionar acerca de con qué trampas se tienen más dificultades y con cuáles hay un mejor manejo, a la vez que tenemos en cuenta qué roles se desempeñan en los diferentes sistemas de pertenencia. Es muy probable que, en función del rol que se desempeñe en la familia de origen y en otros sistemas de pertenencia (es decir, aquellos roles con los que el profesional se siente reconocido e importante), se tienda a activar este rol ante un discurso $u$ otro de la familia. Así ante una demanda planteada desde la urgencia o desde la dramatización, aquellos profesionales que han ejercido en su familia de origen un papel de hijos parentalizados pueden tender a activar el rol de salvador o el de cuidador. Ante la delegación, una persona que se siente reconocida e identificada con los adjetivos de responsable, resolutivo o eficaz puede ponerse a resolver el problema en lugar de esperar a que sea la familia la que lo resuelva. $Y$ aquellos a los que el conflicto o la discrepancia les generen tensión puede que, ante un pseudoacuerdo, pasen por alto el conflicto de intereses. El resultado de todas estas interacciones es el bloqueo del proceso de cambio, ya que el sistema profesional acaba realizando funciones sustitutorias al ser atrapado por "el cerco de goma de la familia".

En los dos casos anteriormente descritos, donde la familia presenta la demanda desde una 
dramatización minimizada, el riesgo es adoptar una actitud de salvadores de los menores que nos lleve a una confrontación y derive en una escalada simétrica con los progenitores, a la pérdida de la neutralidad, etc. Si no se comprende cuál es el funcionamiento familiar no se entenderá que el niño o la niña acaben apostando por sus progenitores desde el sentimiento de lealtad a la familia, en lugar de aprovechar la ayuda que le ofrece el profesional que hace de portavoz de su sufrimiento con la finalidad de "salvarle". En esta situación, los sentimientos de fracaso, impotencia y traición están servidos para el profesional. Adoptando esta postura, también se pierde la posibilidad de generar oportunidades de cambio para la familia, ya que esta suele acabar resistiéndose a los intentos del profesional de "salvar" a uno de los miembros debido a que no se da la posibilidad de que profesional y familia le otorguen un significado a la violencia o al problema que presentan. Conocer los motivos que llevan a elegir una profesión de ayuda, puede aportar información valiosa acerca de qué rol o roles se activan en la relación con las familias.

\section{Segundo embrollo: la institución pide al profesional que intervenga con familias que no quieren ser intervenidas}

Otro embrollo al que se enfrenta el profesional tiene que ver con las situaciones en las que la petición de cambio es externa a la familia. En estos casos una de las dificultades que tiene que afrontar es lograr la colaboración de la familia. Con frecuencia el profesional se encuentra con una familia que no ha realizado una demanda explícita de intervención terapéutica, sino que es "derivada” por otros profesionales que han detectado una dificultad o un problema susceptible de intervención desde otro contexto profesional. El profesional, por tanto, se encuentra teniendo que responder a una demanda que ha realizado otro profesional para la familia y con una familia que no manifiesta un deseo de trabajar en aquello que otro profesional ha pedido para ella. Siguiendo a Cirillo (1991) que la familia no lo demande explícitamente no quiere decir que no desee cambiar.
Tres son los elementos a tener en cuenta en la intervención con las familias multiasistidas cuando esta tiene lugar en una institución y sobre los que tenemos capacidad de actuación para comenzar a promover el cambio (Cuadro 1). Estos elementos se dan en la interacción entre el sistema familiar y el sistema profesional: el contexto en el que tiene lugar la intervención; la demanda de la familia y de otros profesionales sobre esa familia y la capacidad de establecer una alianza o un vínculo terapéutico. Ambos, familia y profesional, han de respetar el marco de trabajo donde tiene lugar la intervención: la institución, que definirá normas para ambos sistemas, así como para la interacción entre ellos. Estas normas suelen tener que ver con la normativa legal, la protección ante posibles situaciones de vulnerabilidad de derechos, con procedimientos, guías y protocolos que hay que respetar, con requisitos a cumplir, temporalidad, con qué es competencia y qué no, etc.

En cuanto al primer elemento, el contexto profesional de cambio, Carlos Lamas lo define como "el marco que se establece entre cliente y profesional y permite dar significado a una serie de intercambios comunicacionales orientados a introducir el cambio en el cliente" (Lamas, 1997: 83-124). Conocer, respetar y ser claros y transparentes con la familia acerca de cuál es el contexto profesional de cambio en el que tiene lugar la intervención es un requisito de obligado cumplimiento para conseguir la colaboración de la familia con la intervención y evitar el deslizamiento de contexto (Selvini, 1990, citado por Rodríguez, 2013: 246).

En las situaciones donde se da vulnerabilidad de derechos, como en los casos descritos, la petición de cambio es externa a la familia, algo habitual en los casos de negligencia o malos tratos, y la demanda la hace un tercero con función de control social. En estos casos, la intervención se enmarca en un contexto coercitivo; esto supone una actitud inicial por parte de la familia de no colaboración con la intervención y esa va a ser la primera dificultad a afrontar por parte del profesional: identificar esas actitudes iniciales que la familia trae y lograr su colaboración.
Contexto

Demanda

Amenaza
Sistema profesional 


\subsection{Claves para el manejo de la no voluntariedad}

En el caso de Ángela, el primer contacto de la familia con los servicios sociales fue una solicitud de ayuda para vivienda hace seis años cuando llegaron al municipio. Tras el episodio del padre con la hija, la madre se acerca de nuevo a la trabajadora social, le describe lo ocurrido y le solicita ayuda para el marido porque está durmiendo en la calle. A la vez desde el colegio notifican a servicios sociales que el hijo de seis años acude en muchas ocasiones con falta de higiene, presenta un retraso madurativo tanto en el habla como en psicomotricidad y que el hijo mediano, de once años, resuelve los conflictos con iguales usando la violencia. La derivación a nuestro servicio surge de la crisis en la familia debida a la situación de violencia del padre hacia la hija, provocando su salida del domicilio. La trabajadora social solicita una evaluación de la situación familiar.

En el segundo caso, el de Mikel, nos encontramos con una familia en crisis por el ingreso en prisión del padre. El primer contacto de la familia con servicios sociales se produce a raíz de la orden de protección hacia el padre; la madre vive en una pensión donde, a pesar de constar orden de alejamiento, mantiene contactos con el padre y los hijos. Para el pago de la pensión demanda ayuda económica a la trabajadora social. La trabajadora social a petición del juzgado solicita la evaluación de la situación del menor. Vemos que en los dos casos los servicios sociales reciben por un lado una demanda de las familias (relacionadas con la vivienda) y por otro lado una demanda de otras instituciones: de la escuela en el primer caso y del juzgado en el segundo. Esto es importante tenerlo en cuenta porque de cara a la intervención será necesario conectar lo que preocupa a la familia y lo que preocupa a la institución, que generalmente no suelen coincidir.

En los dos casos presentados se explicitan los hechos en las sesiones; además, la red de profesionales que intervienen trabaja para que la familia tome conciencia de la gravedad de los hechos sucedidos, se sitúa como víctima a los hijos y se pone de manifiesto el sufrimiento de todos los miembros de la familia. Es importante prestar atención a cómo se presenta la familia que no quiere ser intervenida porque puede darnos claves para manejar el embrollo. Los dos casos exigen activar un contexto de control pero hay que trabajar de diferente manera, porque la familia presenta los hechos o su gravedad de forma diferente. En el caso de Ángela, la familia responsabiliza a la hija de los problemas cuando dicen "si no hubiera bebido...". El padre no pide ayuda porque está pendiente de juicio. En la primera entrevista cuenta que dio un azote a la hija, que le echó la bronca... Cuando se le lee el informe policial dice que no se acuerda, que tiene una laguna en su memoria de lo que sucedió desde que volvieron del hospital hasta que se presentó la policía en casa. De su relato se observa que acepta la posibilidad de que haya ocurrido, pero niega que haya sido de forma consciente y sitúa la responsabilidad en la hija.
La madre manifiesta que lo que pasó está pasado, que no están afectados. Lo que hizo el marido no le parece proporcional con lo que hizo la hija y busca una explicación de por qué el marido reaccionó así. Duda de si hizo lo correcto o no interponiendo denuncia porque cree que quizás exageró con lo sucedido. En el relato de la madre se observa que acepta los hechos y responsabiliza de ellos al padre, pero minimiza la gravedad y el daño. Para aportar gravedad, se pregunta a la hija en sesión familiar “¿Cómo conseguiste no morir esa noche?".

En el caso de Mikel, la madre y los hijos manifiestan que ya no tienen problemas porque creen que la violencia es consecuencia del consumo de drogas y ya se han puesto en tratamiento. Justifican también el incendio por el consumo y la no disponibilidad inmediata de comunidad terapéutica para el padre. En esta situación se observa en las entrevistas que la familia acepta los hechos, los describe con detalle, pero como algo del pasado, y sitúa la responsabilidad de en terceros, en las instituciones: salud-comunidad terapéutica; oficina de empleo-trabajo, servicios sociales-vivienda, etc. Como la familia exhibe la violencia como algo pasado, ya resuelto, en sesión no se refuerza la exhibición preguntando por detalles, episodios concretos, etc., sino que se insiste en dar gravedad a la situación aquí y ahora. Así, cuando la madre manifiesta que "nos queremos, eso ya está pasado y el niño está bien”, el equipo terapéutico devuelve el mensaje: "sí, os queréis con locura y eso lleva a situaciones de pérdida de control y de riesgo para cada uno de vosotros y para la familia”. Este mensaje es aceptado por la madre y los hijos porque encaja en la imagen que tienen de la familia y de cómo se expresa el afecto, a la vez que se explicita y se pone palabras a la gravedad de la violencia. En la misma línea se exploran las consecuencias del hecho preguntando al hijo: “Entonces, ¿tú lo perdiste todo?”; y a todos, "¿Qué hubiera pasado si hubieseis estado en casa?”.

Con estos mensajes, ambas familias reciben información acerca de que la gravedad de los hechos exige activar un contexto de control, pudiendo otorgarle un significado al encargo del derivante. Las dos familias están sufriendo y para evitarlo intentan pasar página, no afrontan lo sucedido y niegan las consecuencias. Nuestro trabajo consiste en ayudarles a no pasar página, en ir hilvanando para acercar a la familia y la institución, y eso pasa por afrontar los hechos y sus consecuencias para que finalmente puedan otorgarle un significado. El equipo profesional también debe entender y dar un significado a por qué la familia no quiere ser intervenida; en los dos casos expuestos para evitar sufrir y para que con la vuelta del padre a casa se vuelva al equilibrio anterior. En definitiva, el profesional tiene que construir un puente que conecte lo que le pide la institución con algo que preocupe a la familia, es parte del trabajo a realizar para salir del embrollo y poder elaborar una demanda, segundo elemento sobre el que se tiene posibilidad de actuación. En los dos 
casos presentados, ambas familias mostraban preocupación por la crisis que estaba suponiendo la salida del padre del hogar.

En el caso de Ángela, la madre (que se siente más legitimada a pedir ayuda porque protegió a la hija y puede presentarse con una buena imagen), se apoyaba en el primer hijo varón, que manifestaba que la madre no sabía apañarse con las gestiones del hogar, del colegio o con la trabajadora social como lo hacía el padre; incluso afirmaba que si salían de casa para ir a algún sitio con la madre, daban mil rodeos y acababan perdiéndose. La madre daba la razón al hijo a la vez que le pedía paciencia. Esta “queja” permitió elaborar una petición de ayuda para afrontar los cambios que estaban suponiendo para toda la familia el alejamiento "obligado por el juez" del padre. En el caso de Mikel, la madre también se apoyaba en él tras la salida del padre del domicilio y toda la familia expresaba el deseo de volver a estar juntos. Con la salida del padre, el hijo obtiene poder, cree tener la llave que reduzca la posible condena del padre demostrando que no le ha generado ningún daño la situación vivida... Por lo tanto, la demanda de la familia es: "ayúdenos a demostrarle al juez que esto que ha pasado no es grave y no nos ha afectado". Se conecta la petición del juez con la de la familia proponiendo la evaluación del estado emocional del niño, a la vez que se va dando el mensaje de gravedad a la familia desde el relato que hacen, de modo que esta pueda otorgarle un significado y un sentido a la evaluación.

El tercer elemento sobre el que se tiene influencia es la alianza terapéutica. Relvas y Sotero (2014) recomiendan para generarla en estos contextos hablar desde la primera sesión acerca del mandato con vista a negociar los objetivos y los términos de la terapia, así como el tipo de relación que se va a establecer con la familia y con la entidad derivante. Generar una alianza terapéutica, que no es lo mismo que una alianza, exige claridad, transparencia y cierta directividad por parte del profesional que permita definir unas reglas mínimas que regulen cómo va ser la relación con la familia. En caso de que se comparta información con otros profesionales, qué tipo de información en líneas generales se va a compartir, será necesario avisar a la familia en el encuadre de la intervención de que si nos revelan informaciones que supongan riesgo para algún miembro de la familia se trasladará esa información y qué encargo ha realizado la persona derivante. Obviar la explicitación de estas reglas de relación en pro de la alianza es probable que sitúe al profesional a lo largo de la intervención en situaciones de difícil salida.

\section{Tercer embrollo: la relación con otros profesionales o el profesional triangulado}

El profesional que trabaja con familias mutiasistidas con frecuencia se ve envuelto en triángulos (Carl y Jurkovic, 1983), llevándole en ocasiones a situaciones de embrollo similares a las que describía la Escuela de Milán (Selvini et al., 1990). Estas situaciones triangulares se dan cuando bien la familia o el profesional incluyen en la intervención a otro servicio para disipar la tensión y favorece que en ocasiones la familia reciba mensajes contradictorios, aliándose con uno y abandonando al otro. Ante esta situación, si el profesional no ha percibido el juego relacional se sentirá confundido y traicionado. Para que la familia no quede diluida entre los diferentes servicios será necesario construir un contexto de colaboración con el derivante y los otros profesionales intervinientes.

El trabajo con las familias multiasistidas implica asumir que hay otros profesionales que también están trabajando con la familia, ya sea del sistema sanitario, escolar o judicial, etc., profesionales con los que se debe construir el caso e intentar no fragmentar el problema de la familia entre los diferentes servicios (Colapinto, 1995). El manido trabajo en red forma parte del día a día del profesional. Si la red de profesionales es funcional, es muy posible que la familia evolucione positivamente, pero si la red es tan disfuncional como la familia las posibilidades de cronificación de los problemas es alta y también el desgaste del profesional.

Cuando se da un conflicto que genera tensión entre un profesional y la familia y cualquiera de ellos busca a otro profesional que será el tercero en el sistema a tres bandas que diluye la tensión. Si este tercero no se implica lo deseado se buscará a un cuarto o a un quinto... llegando a complejos entramados de redes profesionales donde la familia ya ha diluido totalmente su proceso familiar, delegando sus funciones en los servicios y siendo incapaz de tomar sus propias decisiones. Se da así lo que Douglas Carl y G.J. Jurkovik (1983) definieron como "triángulo entre agencias" para referirse a situaciones triangulares que implican a una familia y a dos sistemas de servicios. Estos triángulos relacionales no solo afectan a las familias, también los profesionales se ven envueltos en ellos. Las familias también tienen la tentación de devorar múltiples sistemas de ayuda estableciendo alianzas con unos profesionales y abandonando a los que no respondan a sus intereses, lo que favorece la homeostasis del sistema familiar, dándose isomorfismos entre el sistema familiar y el sistema profesional al reproducirse en ambos las mismas pautas de interacción, alianzas, coaliciones y disfuncionalidades y perdiendo los profesionales la perspectiva la motivación para el cambio de la familia, con lo que esta podría pensar que sus problemas son muy graves y que no hay solución.

\subsection{Definir relaciones de colaboración entre profesionales previene la triangulación}

Para definir relaciones de colaboración con los otros profesionales es útil manejar las mismas estrategias que con las familias; al fin y al cabo, el sistema 
profesional no deja de ser otro sistema con sus reglas de funcionamiento, sus dinámicas de relación, etc. Algunas de estas estrategias referidas a la relación con los otros profesionales que intervienen en el caso son: conocer y vincularse con los otros profesionales; respetar las reglas de cada uno de los contextos, manejar los posibles deslices de contexto, adoptar una posición más discreta cuando sea necesario para definir esa relación de colaboración, saber cuándo echarse para atrás en la silla, desactivar el acciónreacción ante una información que nos impacta emocionalmente, tener en cuenta cómo es la relación de cada profesional con la familia a quién atiende, desde cuándo, etc., son claves que nos ayudarán a dirigirnos a este profesional en forma de escucha y que la hipótesis sobre el funcionamiento familiar sea compartida para construir el caso.

En el caso de Borja, que tiene cinco años, este vive con su madre Elena desde que sus progenitores se separararon cuando él contaba un año de edad. Elena sigue tratamiento en el centro de salud mental por depresiones y ha tenido algunos episodios que han requerido ingreso psiquiátrico. Desde el centro de salud mental, Elena es derivada a los servicios sociales, según el informe de derivación por dificultades en habilidades sociales y falta de autoestima que provoca ansiedad en el ejercicio parental. La trabajadora social solicita intervención terapéutica, motivada por la petición del padre de ayuda psicológica para él y para su hijo. En las entrevistas se observa que la madre presenta dificultades para establecer relaciones de pareja no tóxicas (como las llama ella). Manifiesta que sufrió maltrato psicológico de su última pareja, Fernando, y actualmente también acude a un programa de atención psicológica a mujeres víctimas de violencia de género. Además, cuenta a la trabajadora social que el niño recientemente le ha dicho a su padre en una de las visitas que está contento por no tener que estar más con Fernando, ya que a los juegos que jugaba con él no le gustaban, y que ha dicho que este le ha metido algo en el culo. El padre se pone en contacto con la madre y acuden a la pediatra que le deriva a psiquiatría infantil. Desde allí comunican a la trabajadora social que harán una valoración global del menor (ya estuvo en otra ocasión y se le dio el alta, prescribiéndole un tratamiento con psicomotricista por retraso madurativo). Ambos progenitores han denunciado los hechos en el juzgado y el padre, que actualmente está de baja laboral, solicita apoyo psicológico para su hijo y para él. La trabajadora social le propone nuestro servicio.

La madre y el hijo ya están acudiendo a otros recursos y antes de iniciar la intervención se decide conocer cuál es la visión que tienen los otros profesionales que ya estaban en contacto con la familia. En la reunión estaban presentes los siguientes profesionales:

- La trabajadora social del servicio social de base municipal.

- El perito del juzgado.
- La psicóloga de atención a víctima violencia de género.

- La educadora de los servicios sociales.

- La trabajadora social del centro de salud mental al que acude la madre.

- La trabajadora social del centro de salud mental al que acude la expareja de la madre.

- La psicóloga del servicio social municipal.

No acuden el psicomotricista, ni la tutora, ni la psiquiatra del centro de salud mental que atiende al niño. Las ausencias se justifican por dificultades para organizar la agenda y llama la atención que faltan los profesionales que atienden al niño y acuden los que atienden a la madre. La situación recuerda a la metáfora de Colapinto (2005) y el Olimpo de los profesionales y la posible dilución del proceso familiar entre la institución de profesionales que acaba generando pocas oportunidades para interactuar a los miembros de la familia (madre por un lado, niño por otro y padre por otro). Los profesionales contienen, sufren por la familia, cada uno por el que atiende... y se establecen relaciones significativas con profesionales a expensas de las relaciones internas de la familia (en el caso de la madre era muy evidente). Esto nos lleva a pensar que en caso de que lleguemos a intervenir se hará necesario tener en cuenta la posible triangulación de la familia entre los profesionales que intervenimos. También nos preguntamos qué hacemos nosotras en esta reunión. No conocemos a la familia, no intervenimos con ella... pero nos han solicitado intervenir sobre el padre y el niño. Decidimos mantener una actitud de escucha, recoger información acerca del funcionamiento de la familia y consensuar si tuviéramos que intervenir cuándo y para qué.

Algunas de las informaciones que observamos en la reunión son que los profesionales que trabajan con la madre la definen como una madre sobrepasada con la situación, en actitud de víctima que consigue activar la sobreprotección de los profesionales: todos consideran que su intervención es necesaria y más tras los últimos acontecimientos relatados por el niño. La madre activa muchos recursos, el padre no tantos. La psicóloga de atención a víctimas de violencia de género propone retirarse si comenzásemos la intervención desde infancia. Se consensua esperar al peritaje del juzgado para valorar qué recurso es el más adecuado. Se define una relación de colaboración entre los recursos intervinientes. En la reunión se constata que las intervenciones propuestas no están arrojando los resultados deseados: la educadora refiere no tener más herramientas que aportar, ha agotado todos los recursos de su intervención; la trabajadora social propone el caso a su supervisor externo; la psiquiatra no acude pero la trabajadora social del centro de salud mental deja claro que el centro tiene que seguir interviniendo porque la madre está muy débil emocionalmente. 
Se trabaja por un lado en prevenir la triangulación de la familia entre los recursos intervinientes y la dilución del proceso familiar. Para ello se define una relación de colaboración entre los profesionales, manifestando disponibilidad para intervenir en la medida en que se considere indicado. Por otro lado, se gana tiempo para no responder a la demanda desde la urgencia y que la trabajadora social pueda elaborar una demanda de apoyo psicoterapéutico familiar. Tras el peritaje del juzgado, este concluye que "el menor no está afectado y que no hay prueba de testimonio en relación con abusos sexuales". Los recursos intervinientes consideraban que nuestro servicio tenía que intervenir y aprovechamos la demanda del padre para construir una demanda familiar.

Ya hemos descrito anteriormente que la madre sufría de depresión, por lo que era atendida en el centro de salud mental. Trabajamos con la hipótesis de que la depresión es la responsable de todo el malestar de la familia: del divorcio (dicen que se divorciaron porque ella no se puso en tratamiento), del supuesto abuso del niño (la madre dice que su depresión no le permitió estar atenta a lo que hacía su expareja con el niño), la depresión le hace pedir ayuda a la abuela materna, con la que mantiene una relación conflictiva para la crianza... Pero si no hubiera depresión, ¿cómo obtendría la madre el acercamiento afectivo? ¿Cómo se relacionaría con su madre, con el padre de su hijo? ¿Con su hijo? La depresión atrae a la abuela, atrae al padre y atrae al niño.

La intervención va avanzando y, entre otras cosas, se va quitando poder a la tristeza y dando poder a la alegría. En una de las citas la madre, Elena, insiste en afirmar que "no voy a poder, la educadora no me ha servido, la psicóloga de mujer tampoco me la ha quitado, en el CSM [centro de salud mental] me preguntan si esto está ayudando al niño, como no paro de pelearme con mi madre he empezado a ir a un servicio de mediación pero creo que tampoco va a funcionar...”. La familia busca otro servicio cuando ve que el nuestro no está respondiendo a sus intereses. Al percatarnos del juego relacional que establece la familia con los diferentes servicios (abandona el que no le interesa y se alía con otro nuevo), se convoca una reunión con el servicio de mediación, la trabajadora social y el centro de salud mental (que era el que había derivado a Elena al servicio de mediación). Explicamos nuestra visión del caso e informamos del trabajo que venimos haciendo con todo el sistema familiar. Se desactiva el servicio de mediación, que decide retirarse del caso en esta reunión.

Herrero (2008) proponía la necesidad de que la red sea liderada y el líder ha de ser aquel profesional que esté más cerca de la familia, pero cuando la responsabilidad de la petición no está en la familia, sino en el derivante, y este tiene una función de control social, es el profesional o el servicio que demanda una intervención para la familia quien ha de mantener su posición de responsabilidad específica dentro de la red. Las reuniones de red junto con la familia (al principio de la intervención o cuando hay atascos) y convocadas por el responsable de la red, también son un instrumento de trabajo útil para evitar los triángulos entre servicios. El hecho de que la familia esté presente suele producir reparos a algunos profesionales pero da coherencia a la constitución de la red. Estas reuniones que no son habituales en la práctica profesional son muy útiles por varios motivos: introducen a la familia en el proceso de toma de decisiones sobre su vida, obligan a utilizar un lenguaje sencillo para que esta pueda participar con protagonismo y disminuyen la competitividad entre profesionales, ya que si la familia siente o sabe que los profesionales hablan de ellos sin estar presentes tienden a pensar que el cambio no depende de ellos sino que la gestión del cambio se realiza desde fuera, etc. Finalmente, siguiendo también a Herrero (2008), la red debe ser una orquesta que toca una misma obra musical con distintos instrumentos y distintas partituras: si la orquesta es pequeña resulta más fácil que suene bien; si es grande, hace falta un director importante; si es demasiado grande, la familia no toca, se diluye en el conjunto.

\section{Cuarto embrollo: la burocratización de la intervención}

La progresiva burocratización de la intervención a la que asistimos en los servicios sociales condiciona los procesos de cambio en la medida en que define la relación del profesional con las familias y la relación entre los profesionales de los diferentes recursos que "consumen" las personas usuarias de los servicios sociales. El procedimiento nos estructura la actividad, nos da seguridad, nos da vocabulario para explicar a la persona usuaria en qué categoría está su problema y qué va a pasar, es decir, cuál es el siguiente paso. En el paisaje actual los profesionales nos encontramos sujetos al procedimiento, a los tiempos, a la eficacia y a la eficiencia de la intervención, etc. Asistimos actualmente a la proliferación de guías, manuales, procedimientos, normas de calidad, etc., que son requisitos de obligado cumplimiento para el profesional, ya sea a través de decretos, normas de la organización a la que se pertenece o a la administración para la que se trabaja. Esperanza Molleda (2007), en su artículo "¿Por qué decimos que 'no podemos hacer intervención social'?”, señalaba en este sentido:

Se definen fácilmente objetivos, se establecen rápidamente plazos, incluso los recursos y los instrumentos que vamos a utilizar, pero no encontramos grandes indicaciones de cómo conseguir cambios. Hay cierta fe en que solo con definir unos objetivos y poner a disposición del sujeto unos recursos la situación va a cambiar. A menudo dice, esto no ocurre, las cosas no cambian y los casos se cronifican... Nos agarramos al modelo médico que nos hace esperar que se pueda encontrar un recurso-medicina para cada 
necesidad-enfermedad, nos inspiramos en la lógica administrativa aspirando a definir con precisión los procedimientos más adecuados, y recurrimos al pensamiento económico para pensar en términos de utilidad, rentabilidad y eficacia en todas nuestras acciones. Pero, al final, seguimos librados a nuestra suerte en el grueso de nuestro trabajo: el cuerpo a cuerpo con las personas que demandan soluciones a sus problemas. $Y$ tres son las herramientas con las que contamos para este trabajo: la relación profesional, la palabra y los recursos y mucho lo que hay que pensar todavía sobre ellas. Para la autora, la burocracia no es el problema en sí mismo, sino que el verdadero problema es "el uso que hacemos de ella para evitar encontrarnos con la complejidad y las contradicciones de la tarea. (Molleda, 2007: 149)

\subsection{Cómo afectan los protocolos a los procesos de dilución familiar, a la intervención hacia el cambio y a la interacción familia-profesional}

A priori, contar con un procedimiento, una norma de calidad, inviste de cierta profesionalidad y neutralidad; en ocasiones se inviste al procedimiento de una capacidad imposible llegando incluso al absurdo de creer que si un profesional abandona su puesto de trabajo por las razones que sea, el que le sustituya podrá comenzar la intervención en el punto de partida donde lo dejó el anterior... es decir, podría no ser necesario ser un profesional con cierto manejo de la relación terapéutica, la escucha activa, el análisis de la función del problema en el contexto en el que tiene lugar, etc. Sería suficiente con conocer el protocolo, el procedimiento y saber a dónde derivar. Este espejismo, fruto del exceso de burocratización de la intervención, tiene consecuencias para ella. Cabe preguntarnos si algunas de estas consecuencias tienen algo que ver con el proceso diluidor de los servicios sociales que ha desarrollado Colapinto (1996), con los isomorfismos que comenta Coletti (1995), con las familias multiservicio de Black (1988) o con los procesos de triangulación entre agencias de Carl y Jurkovik (1983).

El o la profesional como miembro de la institución ha de incorporar en el trabajo con la persona usuaria los instrumentos propios de la intervención en el sistema de servicios sociales, instrumentos que suelen partir de los déficits, que tratan de categorizar el tipo y gravedad de "alarma" generada para poder tomar decisiones. El profesional se presenta ante el usuario con el código de su disciplina, pero por encima de este código se inviste o es investido de códigos que tratan de categorizar, definir el circuito que seguirá la familia o la persona usuaria en función de la categoría asignada. La complejidad que presentan las familias trata de ser reducida a la categorización del problema presentado, a la designación de la institución o el departamento responsable de esa categoría, se sustituye la comprensión de lo que sucede (el quién, el cómo, el cuándo, el dónde, etc.) por el sitio donde ha de ser atendido o por el nivel de gravedad que presenta... La complejidad de las situaciones de las familias es en muchas ocasiones repartida derivada y troceada entre servicios.

Si nos acomodamos en exceso a la percepción de la persona usuaria de los servicios sociales como posible "consumidora" de las diferentes prestaciones que ofrece el sistema en función del "problema que presenta”, podemos entender algunas de las situaciones de dilución de procesos familiares. Así, por ejemplo, en el caso de la familia de Borja descrito anteriormente, al preguntar a la madre qué podía hacer ella para dirigir la conducta de su hijo refirió en una entrevista: "Mi problema es tan grave que no se puede solucionar; la otra psicóloga no me ha quitado la dependencia a mi expareja, la trabajadora social no consigue que me den la ayuda; ir donde la educadora no ha servido para que el niño se porte bien; la psiquiatra no acierta con la medicación y venir aquí tampoco me está ayudando". No hace falta explicar la agenda de esta persona, víctima de los procesos de derivación entre diferentes recursos y prestaciones. En función de la puerta a la que llamase para pedir ayuda, su problema era interpretado según la especialidad del recurso. Como al poco de iniciar la intervención aparecían "otros problemas asociados", se la derivaba a otro recurso y así sucesivamente...con ella iban el hijo, la madre o el padre del hijo, dependiendo del recurso y su contexto de intervención. En este caso, la relación entre los diferentes profesionales que atendían al niño y a su familia estaba mediatizada por el protocolo de derivación entre servicios, es decir, primero se trataba la cuestión de qué institución y qué profesional tenía competencia sobre cada uno de los problemas y, en segundo lugar, si se cumplían los requisitos para ser atendida en el servicio. Para cuando los profesionales pueden ponerse a hablar del caso, la familia se ha convertido en una experta del manejo de la red, cuenta en cada servicio, acomodándose a él, lo que el contexto del servicio ha "contratado" con ella, sin dar demasiada información de lo que explica en otros servicios. La fragmentación del problema, la dilución del proceso de vida de Borja y su familia, están garantizados, así como la explicación que a veces nos damos los profesionales ante las dificultades de colaboración de las familias: la resistencia al cambio.

Una de las preguntas más habituales que suelen hacerse los profesionales cuando se reúnen para tratar un caso es: ¿es competencia de este servicio? Unida a la pregunta de a quién corresponde intervenir en ocasiones aparece implícita en el profesional que recibe el caso la idea de que “ ¡claro! es que no se quiere hacer cargo porque es un marronazo". No podemos olvidar que tratamos con problemáticas graves, de impacto emocional intenso, que en ocasiones hacen tambalearse todas nuestras referencias, y cuanto más tiempo dediquemos a dilucidar quién se hace cargo del caso, menos tiempo dedicamos a construir el caso con el otro, a hablar de lo que la familia parece necesitar y de lo que se puede hacer desde cada contexto. 
A veces, amparándonos en lo competencial, nos desentendemos del caso porque nos provoca emoción de rechazo, de impotencia, etc., y buscamos dónde derivarlo o qué programa especializado hay. Si lo derivamos porque nos sobrepasa, la familia puede acabar siendo una familia a la deriva. Otras veces, amparándonos en lo competencial, nos quedamos con el caso no siendo de nuestra competencia, no respetando el marco de actuación ya que según normativa no podríamos intervenir y, sin embargo, seguimos interviniendo.

En estas situaciones puede estar implícita la sobreimplicación emocional, la pena por la familia, y la desconfianza en los otros profesionales: “¿para qué lo vamos a enviar allí, si no van a hacer nada diferente?" o también el sentimiento de fracaso del terapeuta cuando lleva mucho tiempo interviniendo con la familia ("he hecho mucho por ella y no ha cambiado, ha ido a peor"). Surgen resistencias a derivarla ya que supone enfrentarse al fracaso, una de las emociones más duras para el profesional, que se siente sobrepasado por una exigencia demasiado alta (Coletti, 1995). Al final dirige la emoción y en función de la emoción que suscita el caso y de cómo se maneja se puede pervertir lo que es competencia o lo que no, y el resultado del no respeto a las normas del contexto, de la institución, coloca al profesional en una situación complicada.

\subsection{Pequeños pasos hacia el cambio: la intervención va más allá del procedimiento}

A veces el procedimiento enmascara la intervención. Se puede seguir el procedimiento y realizar una intervención eficaz, pero también se puede seguir el procedimiento y que la intervención no sea eficaz. Cuando surgen dificultades que suponen alarma o escandalo social, generalmente se suele poner el foco en si se ha seguido el procedimiento y no tanto en el tipo de intervención realizada. El profesional se encuentra ante la disonancia entre el mandato organizacional y la demanda planteada por el usuario, para ello se hace necesario encajar esta demanda en la norma, en la categorización, en el procedimiento a seguir. Sin embargo, no todas las demandas o todas las características de la demanda encajan como un guante en la norma. Ante esta disyuntiva, el profesional puede buscar excepciones a la norma para intentar cuadrar el círculo; otras veces puede aplicar la norma sin valorar otros aspectos que acompañan a la demanda y a la situación familiar, otorgando aquello cuyos requisitos se cumplen y denegando lo que no está contemplado.

La otra opción es cumplir con los requisitos de la norma, valorar y categorizar el caso pero sin olvidar cuál es la demanda de la persona usuaria, que no pregunta a qué ventanilla tiene que ir sino que está pidiendo ayuda para resolver un problema que le está generando sufrimiento. Esto supone incluir en las interacciones con la persona usuaria a otros protagonistas: la escucha, la alianza terapéutica, tener en cuenta cuál es la función del síntoma, quién sufre, quién pide ayuda, teoría que nos ayude a entender determinados juegos relacionales, etc. ¿Puede el profesional introducir estas variables además de la aplicación del protocolo? Habrá que hacerlo si queremos introducir cambios.

El profesional no puede no respetar los procedimientos del sistema al que pertenece, ya que se convertiría en un irresponsable y un temerario, generando dificultades al sistema al que pertenece, a la persona usuaria y a la relación con otros profesionales. Pero tampoco podemos confundir el procedimiento, el protocolo, con la intervención; no debemos confundir el fondo con la figura. Una cosa es situar cada caso en el sitio que le corresponde y otra confundir la intervención con la asignación de competencias... confundir la estructura de la organización/administración con la intervención. Lo que produce cambios es la relación, no el procedimiento; por ejemplo, a veces se confunde elaborar y trabajar con el genograma con tenerlo apuntado, registrado, cuando la elaboración del genograma con la familia supone la elaboración de una narrativa de la propia historia, la expresión de las emociones asociadas a ella, la explicitación de roles, reglas, comunicación, relaciones significativas, etc. ¿Dónde queda todo esto cuando incluimos el genograma como un requisito a rellenar en un registro?

Cecchin, Lane y Ray nos proponen la irreverencia como una forma de conservar la salud cuando intentamos satisfacer tanto a la institución como al cliente. Nos advierten de los peligros de obedecer a la institución al pie de la letra, porque equivale a convertirse en un robot burocrático y de los peligros de atender únicamente al cliente porque implica convertirse en un revolucionario (Cecchin, Lane y Ray, 2002: 53)

Dedicar tiempo a definir relaciones de colaboración con las personas usuarias y entre profesionales ha de ser la máxima a seguir en las interacciones entre profesionales, así como entre profesionales y personas usuarias. Esto supone, entre otras cosas, dedicar tiempo en la entrevista o en la reunión a la escucha y registrar la información posteriormente, o hablar el lenguaje de la familia en lugar del lenguaje del protocolo. Para poder hablar el lenguaje de la familia, el profesional ha de dedicar tiempo y esfuerzo a la alianza terapeutica, a la acomodación, etc. En general, los profesionales que trabajamos en los servicios sociales contamos con diferentes programas, diferentes recursos, servicios, etc. Somos muchos, así que mejor colaborar y sumar fuerzas que "derivarnos" a las personas usuarias, eso sí, cumpliendo el procedimiento pero sabiendo que es algo así como el trasfondo. No podemos culpar al procedimiento de todos los males y convertirlo en un mito de disculpa, ni considerarlo la piedra filosofal y forjar un mito de salvación. 


\section{Quinto embrollo: la asincronía profesional-familia}

En ocasiones, los profesionales corremos algunos riesgos que dificultan el proceso de cambio. A veces, podemos vernos tentados a empujar a la familia hacia el cambio cuando ella no quiere cambiar... o cuando el ritmo de la familia hacia el cambio es lento. Otras veces, podemos pedirles cambios demasiados grandes para lo que pueden tolerar en cuanto a pérdida de identidad, red social, etc. Las familias, los profesionales y los servicios tienen diferentes unidades de medida y distintas percepciones del tiempo en que deben afrontarse los problemas, lo que da lugar a una asincronía entre profesional y familia. "Los 'tiempos de la familia' suelen ser lentos [...], los 'tiempos del profesional' van más en la línea de cambios rápidos ligados a la necesidad de demostrar eficacia, proyectar una buena imagen, prestigio..." (González Calvo 2004: 152) sobre todo cuando se tiene poca experiencia o se lleva poco tiempo trabajando con estas familias.

Hemos de entender que "el cambio en estas familias es un proceso discontinuo contrapuesto a una noción de cambio lineal, gradual, progresivo y acumulativo" (Gómez, Muñoz y Haz, 2007: 8). Esta forma de cambiar en ocasiones genera irritabilidad al profesional en el momento de estancamiento de la familia y la irritabilidad puede hacerle perder de vista el punto de donde partía la familia y lo que ha conseguido. Por ello es necesario respetar los tiempos y tolerar la espera para que sea la familia la protagonista de su proceso de cambio. De lo contrario, profesional y familia se encontrarán en páginas diferentes del libro. Si esto ocurre, el profesional perderá la oportunidad de reforzar las capacidades y competencias de la familia. En el caso de Ángela, la familia, tras año y medio de intervención terapéutica, decidió trasladarse a otro municipio, lo que en nuestro servicio conlleva interrumpir la intervención que se venía llevando a cabo. A los dos años la madre regresó y solicitó ayuda tras la ruptura de pareja.

Por otra parte, el profesional suele tener un plan de intervención que a veces no ha sido construido con la familia, sino que ha sido diseñado para la familia, pero sin la familia. En otras ocasiones el plan de intervención no solo se construye sin la familia sino también sin el profesional que lo tiene que llevar a cabo; es decir, que viene dado por otros profesionales, lo que suele aumentar más la angustia ante la pasividad de la familia, ya que el profesional tiene que dar cuentas de la evolución de ese plan de intervención. Con frecuencia el profesional se siente presionado por la urgencia para solucionar los problemas de la familia. Esta presión proviene tanto de los superiores jerárquicos como del agente derivante, que en algunos casos es quien establece los objetivos de intervención que el profesional tiene que trabajar con la familia. A menudo estos objetivos suelen ser muy ambiciosos para conseguir cambios a corto plazo; unos meses después de comenzar la intervención se revisa su cumplimiento y lo habitual es que no se hayan cumplido. Esto hace al profesional sentirse cuestionado en su saber hacer porque no solo no logra los objetivos definidos para la familia, sino que tampoco cumple con el encargo realizado por el agente derivante. Esta situación recuerda a la metáfora de Mara Selvini del "mago sin magia” (Selvini, 2004) donde explica la paradoja que supone la tendencia del sistema a reducir las dificultades de la familia y depositar en el profesional la responsabilidad de cambiar mágicamente esas dificultades. Así, la institución no tiene la necesidad de cuestionar su propio funcionamiento y el profesional se convierte en cómplice de este. Si su intervención consigue el cambio deseado en la persona con dificultades legitima el modelo de trabajo. Si no lo consigue, es responsable de su propia incompetencia, lo cual protege a la institución de cualquier necesidad de cambio.

A veces nos enfrentamos a casos crónicos en el trabajo con las familias multiasistidas, familias que llevan muchos años, incluso generaciones, de relación con el sistema profesional y que tienen mucha experiencia en la relación con los profesionales. Según Coletti muchas veces el profesional se enfrenta a situaciones graves y de carácter crónico que generan ansiedad y sensación de que no es posible que la situación cambie. "Esta vivencia provoca en el profesional sentimientos de rendición o de resignación" (Coletti, 1997: 209), lo que puede llevar a que repita la misma intervención ante la misma demanda, sin pararse a reflexionar si la misma respuesta ante la misma situación de forma repetida tiene algún sentido. Esta reacción es una forma de negar la ansiedad que produce la cronicidad y la gravedad: "Tengo que hacer algo ante esta situación, ¿y qué más se puede hacer...? Si conozco a la abuela, a la madre y a la hija, y ha sido siempre así”.

La cronicidad es una característica de estas familias, pero también de la relación que se establece entre ellas y los servicios. ¿Qué sería de las familias multiasistidas sin los servicios y que sería de los servicios sin las familias multiasistidas? Para Coletti (1997) las peores vivencias para el profesional suelen ser las recaídas, por el sentimiento de impotencia y de frustración que generan y porque es difícil que el profesional no se atribuya una responsabilidad que le sobrepasa ampliamente. El fracaso produce gran desilusión. En el caso de la familia de Esmeralda, formada por Esmeralda y José, ambos de 61 años, su hija María de 27 años, y el hijo de esta, de 16 meses. El hijo mayor, Andrés, se ha ido de casa cuatro meses antes de iniciar la intervención y vive en otra comunidad autónoma con su novio. El padre del niño acude los domingos a visitarle y María pasa la tarde con ellos. Esmeralda años acude varias veces a la trabajadora social de los servicios sociales de base. En el año 2004, acude planteando desavenencias conyugales y con sus hijos. Manifiesta que quizá está pagando con los hijos el malestar matrimonial, que se siente maltratada por todos, sobre todo por 
su marido, que no la respetaban, ni la valoraban y que la insultaban. En la entrevista surge que a veces se ha excedido con el alcohol. La señora no vuelve a otras citas hasta 2013, que acude con su hija de 26 años, planteando que la hija está embarazada de seis meses, que María y su pareja han decidido que esta va a residir con los padres entre semana y los fines de semana con el padre del niño. Preguntan por ayudas económicas. En marzo de 2014, Esmeralda acude de nuevo preocupada porque considera que no existe una buena relación entre su hija y la pareja; que ve a la hija muy triste y deprimida y que ya no va los fines de semana al domicilio de este con el hijo. Los domingos por la tarde el padre visita al niño y pasan los tres juntos la tarde. Cuatro meses después, acude de nuevo Esmeralda a la trabajadora social planteando un conflicto familiar provocado por la actitud de su hija, ya que considera que el padre del niño la maltrata emocionalmente y luego esta lo paga con ellos. Todos acaban discutiendo y en una ocasión se presentó la policía en el domicilio alertada por algún vecino debido a los gritos de María. Manifiesta preocupación por cómo puede afectar al nieto el ambiente conflictivo que hay en la familia y pide ayuda para esto.

Se observa que en las diferentes entrevistas Esmeralda acude a servicios sociales pidiendo ayuda para la hija o para el nieto. La trabajadora social solicita la intervención de nuestro servicio para trabajar el conflicto familiar e informa de que la señora ha avisado que los otros miembros de la familia no van a querer ir a la psicóloga porque dicen que "la loca es ella"; ella misma tampoco ha conseguido que el señor acuda y la hija ha faltado a muchas citas. Con las características de esta demanda (la ansiosa petición de Esmeralda, la reticencia de la hija que a veces acudía a las citas y a veces no, la ausencia y relativo desinterés del padre que no acudía cuando se le convocaba), se trató de implicar a Esmeralda como portadora de la convocatoria para que fuese ella quien trajera a los otros miembros de la familia a sesión intentando hacer algo diferente ante la demanda repetida de la señora.

Para ello se la citó a entrevista individual, expresando empatía con su sufrimiento; se la trató como paciente necesitada de cuidados pero sin caer en el dramatismo ni posicionándonos de parte de ningún miembro de la familia. Se trataba de construir un vínculo emocional en la relación terapeutapaciente. Esto permitió redefinir relacionalmente los problemas y hablar sobre la importancia de contar con los otros miembros de la familia para tratar las dificultades de esta y finalmente aceptó que padre e hija acudiesen a una entrevista familiar. Se le dio una cita para toda la familia y se le informó de que las sesiones familiares serían llevadas por dos psicólogas. Se contactó telefónicamente tanto con el padre como con la hija para invitarlos a la sesión. La coterapia se planteó para manejar los intentos de alianzas y triangulaciones, al haber tenido dos sesiones individuales con la señora previas a las familiares.
En los casos crónicos habrá que lidiar con las resistencias al cambio por parte de las familias. En este caso, a lo largo de la intervención hubo que manejar diferentes tipos de resistencias al cambio. Por un lado, hubo intentos de triangulación de las coterapeutas: al inicio del proceso la coterapia ayudó a manejar los intentos de triangulación de Esmeralda, que buscaba a "su terapeuta". Se planteó de la siguiente manera: la fase social la inicia la terapeuta que no ha visto a Esmeralda de forma individual. Se acordó que fuese ella quien se encargara más de vincularse con la señora y se manejó la comunicación analógica además de la digital. Cuando la terapeuta preguntaba a la señora, le respondía a la que consideraba la "suya", que abría el foco a los otros miembros de la familia. Una terapeuta se alía con el padre y la otra terapeuta con la madre. Esmeralda trae bombones en la tercera sesión y se rechazan los bombones. Cuando finalizan las sesiones pide disculpas por haber molestado. Se le pide que deje de disculparse al final de las sesiones: "Nos molesta que se disculpe". Dejó de hacerlo. También hubo que manejar las descalificaciones a la competencia profesional de las terapeutas: "No puedo dormir por la noche y escucho a la psicóloga de la radio que me está ayudando mucho"; "Creo que mi hija necesita ir a una psicóloga...”. Ante estas descalificaciones no se responde a la defensiva para evitar una escalada que promueva la resistencia de la familia, sino que se recurre al humor sin que resulte ofensivo: "Pues cómo vas a dormir escuchando a la psicóloga... eso desvela a cualquiera"; "Si te está sirviendo, toda ayuda es bienvenida”. Además, los intentos por parte de Esmeralda de dominar el espacio terapéutico se controlaban dando voz a los otros miembros de la familia.

Estos casos crónicos pueden generar en la profesional irritabilidad al tener que hacer frente a las resistencias al cambio comentadas. Desde la irritabilidad podemos caer en la tentación de dar el caso por perdido o de tratar de "empujar" o "sustituir" a la familia en su proceso hacia el cambio, dándose así también una asincronía entre el sistema familiar y el sistema profesional.

\section{Conclusiones}

La intervención con las familias multiasistidas exige tener en cuenta y saber moverse igual que en un circo de tres o incluso más pistas: en una pista tenemos a la familia, con sus problemas de toxicomanías, desempleo, desahucios, estilos negligentes de crianza, abandonos, violencia, etc., problemas que a veces se arrastran de generación en generación, con pocas expectativas de cambio y que a menudo ven a los profesionales como intrusos que les niegan ayuda económica o vivienda, les quitan a los hijos, les censuran... De ahí que muchas veces no suelen hacer una demanda e incluso rechazan la ayuda, siendo esta impuesta por otras instituciones. Para los profesionales estas familias requieren de una gran inversión psíquica y emocional generalmente con poca recompensa (Escartín Caparrós, 2004). 
Otra pista serían las exigencias y obligaciones que marca la institución en la que el profesional trabaja, que tiene unos fines, una ideología, una cultura, su propio marco normativo y competencial, y que pretende rentabilizar el trabajo, es decir, que se administren bien los recursos, y en los últimos tiempos demostrar también la eficacia y eficiencia del trabajo realizado. Esto se complejiza si además el profesional pertenece a una entidad que presta servicios a la institución, que también tiene sus fines, su ideología, su cultura y su propia organización. La tercera pista la configurarían los diferentes servicios y profesionales que intervienen con la misma familia. Tal como señala Colapinto (1995), algo característico de estas familias es que su problema está repartido entre varios servicios que no siempre comparten qué tipo de cambio deben realizar, quién lidera la intervención, de quién es competencia el caso, puede que haya discrepancia en los objetivos a trabajar, etc. Estas discrepancias no benefician a la familia, sino que contribuyen a la cronificación de los problemas y al mismo tiempo al desgaste de los profesionales.

En el trabajo con estas familias va a ser indispensable tener en cuenta las diferentes pistas. Cada una tiene sus propias reglas, lógicas distintas y cierta autonomía, pero todas presentan grandes conexiones entre sí. Pistas que, en función de los acontecimientos, pueden convertirse en centrales 0 en periféricas. En algunos momentos el profesional tendrá que hacer de trapecista, en otros de cuentacuentos, domador de leones o payaso triste según las circunstancias... Moverse al igual que en un circo de varias pistas conlleva, por tanto, un alto riesgo emocional, por lo que serán necesarios dispositivos adecuados de protección y apoyo.

El profesional tendrá que cuidarse si quiere atender bien a las familias y tomar distancia suele ser de gran ayuda. Para poder mantener esa distancia óptima va a ser necesario legitimar las emociones que nos provocan las familias, además de trabajar en equipo para evitar enredarse en las actuaciones y permitir que el equipo nos saque del cerco de goma de la familia, No conviene con estas familias trabajar como si el profesional fuese el llanero solitario. Ahora bien, aunque es cierto que el equipo puede ser un apoyo para manejar las emociones también puede serlo para todo lo contrario. Para que el equipo no se convierta en otra fuente de ansiedad es necesario que resuelva sus propios conflictos ya que, si no, estos afloran en la intervención con la familia.

También es necesario comprender antes de actuar para que las conversaciones con las familias multiproblemáticas lleven a un discurso para una acción reflexiva y no transformativa, como explica Ramos. Es decir que los profesionales sean capaces de activar a la familia y no al revés, que la familia active al profesional en la solución de sus problemas. El profesional necesitará de un mapa que le oriente y guíe, porque sin mapa es muy probable que acabe yendo donde no quería. En la sistémica contamos con la elaboración de hipótesis que ayuda al profesional a comprender antes de actuar. Dado que el mapa no es el territorio, el profesional tendrá que ir contrastando las hipótesis en la interacción con la familia.

Otro elemento a tener en cuenta es no olvidarse de conferir poder a la familia. Para "otorgar poder a las familias, los profesionales hemos de despojarnos de poder y un modo de hacerlo consiste en buscar recursos dentro de la familia en lugar de derivarla automáticamente" a un recurso (Minuchin et al., 2000: 79-80). El trabajo personal ayuda a entender desde donde elegimos la profesión, manejarnos con la mochila que llevamos en la interacción con la familia, etc. Colaborar con otros profesionales y, por supuesto, formarnos, reciclarnos y supervisar nuestro trabajo. 
ABEIJON, J.A (1987): “Los sistemas en la demanda del toxicómano", Comunidad y Drogas, 1987. Monografía no 1, Madrid.

ALMIRALL FERRAN, R. (2016): INTERXARXES. El trabajo en red mediante la conversación y la construcción del caso, shttp://www.interxarxes.com/wp-content/ uploads/2017/10/03.-presentacin-interxarxescongreso-madrid-2016-r_almirall.pdf〉.

BERGMAN, J.S. (1987): Pescando barracudas: pragmatica de la terapia sistemica breve, Barcelona, Paidós.

CAMPANINI, A.M. (2012): La intervención sistémica: un modelo operativo para el servicio social. Buenos Aires, Mio y Davila, Edición Kindle.

CARDONA, J. (2012): La definición del contexto de intervención en el trabajo social de casos, Departamento de Psicología, Universidad de las Islas Baleares, «http://dfts.uib.cat/ digitalAssets/286/286359_Cardona_Cardona_ Josefa.pdf $\rangle$.

CIRILLO, S. (2012): Malos padres: Modelos de intervención para recuperar la capacidad de ser madre $y$ padre, Barcelona, Gedisa.

CIRILLO, S. y DI BLASIO, P. (1991): Niños maltratados, Barcelona, Paidós.

COLAPINTO, J. (1996): “La dilución del proceso familiar en los servicios sociales: implicaciones para el tratamiento de las familias negligentes", Redes: Revista de Psicoterapia Relacional e Intervenciones Sociales, 1996, Vol. 1, № 2 (2은 semestre), págs. 9-36.

COLAPINTO, J. (2005): El niño entre la familia y el Estado, 〈http://www.colapinto.com/EnEspanol.html〉.

COLETTI, M. y LINARES, J.L. (2007): La intervención sistémica en los servicios sociales ante la familia multiproblemática, Barcelona, Paidós Ibérica.
ESCARPIN CAPARROS, M.J. (2004): Familias multiproblemáticas y servicios sociales, 〈https://es.scribd.com/document/360521457/ Familias-Multiproblematicas-y-ServiciosSociales〉.

ESCUDERO, V. (2010): Guía práctica para la intervención familiar, Junta de Castilla y León Consejería de Familia e Igualdad de Oportunidades Gerencia de Servicios Sociales, «http:// uiicf.net/wpcontent/uploads/2014/06/ Gu\%C3\%ADaPr\%C3\%A1cticalF_VEscudero. pdf〉.

GONZÁLEZ CALVO, V. (2004): "Familias multiproblemáticas, dificultades de abordaje", Revista no 6 del Departamento de Trabajo Social, Facultad de Ciencias Humanas, Universidad Nacional de Colombia, «https://www.google.com/url?sa=t\& $r c t=j \& q=\& e s r c=s \&$ source $=w e b \& c d=2 \& v e d=2 a$ hUKEwiM2529hJ7gAhUvxYUKHXI5DOQQFjABeg QIAhAC\&url=https\%3A\%2F\%2Fdialnet.unirioja. es\%2Fdescarga\%2Farticulo\%2F4390486. pdf\&usg=AOvVaw3-7WlIJG5h6kKY9PlqF6MW .

GÓMEZ, E., MUÑOZ, M. y HAZ, A.M. (2007): “Familias multiproblemáticas y en riesgo social: características e intervención”, Psykhe, 16(2), 〈http://www.emprendimientossolidarios. uc.cl/images/Articulos_WebCEES/2007_ Familias $\% 20$ Multiproblematicas $\% 20 y \% 20$ en $\% 20$ Riesgo\%20Social\%20-\%20Gomez\%20 Munoz\%20y\%2oHaz.pdf〉.

GIONAVAZZI, S., (2009): “Escenas que paralizan: el impasse terapéutico en psicoterapias dramáticas”, en Violencia familiar, Bogotá, Universidad del Rosario.

GUY, J. (1987): La vida personal del terapeuta: el impacto de la práctica clínica en las emociones y vivencias del terapeuta, Barcelona, Paidós. 
HERRERO, P. (2008), La red inteligente, Gobierno Vasco, 〈https://dialnet.unirioja.es/servlet/ articulo? codigo $=2695578$.

IMBER-BLACK, E. (2000), Familias y sistemas amplios, Buenos Aires Amorrortu.

JURKOVIC, G.I. y CARL, D. (1983): “Agency triangles: Problems in agency-familiy relationships", Family Process, 1983, no- 22.

MASSON, O. (1987): “Contextos maltratantes en la infancia y coordinación institucional”, A.E.N, vol. VII, no 23, págs. 531-556, 〈http://documentacion. aen.es/pdf/revista-aen/1987/revista-23/02contextos-maltratantes-en-la-infancia-ycoordinacion-interinstitucional.pdf».

MINUCHIN, S. (1971): Families of the slums: an exploration of their structure and treatment, New York, Basic Books.

MINUCHIN, S. (1974): Familias y terapia familiar, Barcelona, Gedisa.

MINUCHIN, P., COLAPINTO, J. y MINUCHIN, S. (2009): Pobreza, institución, familia, Buenos Aires, Amorrortu.

MOLLEDA, E. (2007): “¿Por qué decimos que 'no podemos hacer intervención social'?", Cuadernos de Trabajo Social Vol. 20, 2007. P. 139-155, 〈https://revistas.ucm.es/index.php/CUTS/ article/download/CUTSo707110139A/7547>.

MONTAGUD MAYOR, X. (2016): “Las consecuencias de la burocratización en las organizaciones de servicios sociales", Comunitania. Revista Internacional de Trabajo Social y Ciencias Sociales, Vol.11, p.70-86, 〈https://doi. org/10.5944/comunitania.11.4'.
NEURBURGER, R. (2003): L'autre demande, Paris, Payot.

RAMOS, R. (2015): Terapia narrativa con familias multiproblemáticas, Madrid, Morata.

RODRÍGUEZ MARTíNEZ, M. (1999): “La familia multiproblemática y el modelo sistémico", Perspectivas sistémicas, $\mathrm{n}-5$, 〈http://www. redsistemica.com.ar/multi.htm >.

RODRÍGUEZ RODRÍGUEZ, A. (2013): Teoría y práctica de la intervención socio-familiar con familias multiproblemáticas, Universidad Complutense, Madrid, 〈http://eprints.ucm.es/17792/〉.

SATIR, V. (2002):Terapia familiar paso a paso; México D.F., Editorial Pax.

SELVINI PALAZZOLLI, M. (1993): Los Juegos psicóticos en la familia, Barcelona, Ediciones Paidós.

SELVINI PALAZZOLI, M. et al. (1988): El mago sin magia. Cómo cambiar la situación paradójica del psicólogo en la escuela, Barcelona, Ediciones Paidós.

SLUZKI, C., 2007: "Lyman C Wynne and the transformation of the field of family-and-schizophrenia", Family Process, 46(2), 143-149. Versión ampliada en castellano en Perspectivas Sistémicas on Line, 〈https://sluzki.com/ publications/articles/147/lyman-c-wynne-andthe-transformation-of-the-field-of-family-andschizophrenias.

WAINSTEIN, M. y WITTNER, V. (2017): “El concepto de familia Multiproblematica y la medición de su funcionalidad/disfuncionalidad", IX Congreso Internacional de Investigación y Práctica Profesional en Psicología, «https://www. aacademica.org/000-067/727.pdf〉. 